\title{
Posicionamento e engajamento em redações dissertativas
}

Maria da Graça Faria*

Mônica Magalhães Cavalcante**

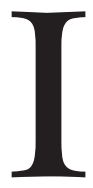

\section{ntrodução}

A noção de metadiscurso, na perspectiva da Linguística Aplicada (LA), é considerada como um conjunto de estratégias discursivas pelas quais os enunciadores se posicionam no texto, marcando suas intenções comunicativas. Em outras palavras, é um modo de organização do texto, com finalidades argumentativas e discursivas.

Vande Kopple (1985) e Crismore (1989) apresentam um ponto comum na concepção de que metadiscurso é o "discurso sobre o discurso". No entanto, é Crismore (1989) quem primeiro postula que o metadiscurso é empregado com a função de orientar o leitor e sinalizar a presença do autor, marcando o seu posicionamento. Veremos que esse pressuposto influenciou sobremaneira os estudos de Hyland (1998) e seguidores.

Essa ótica de considerar o metadiscurso como estratégia de organização do texto é adotada por Hyland (1998, p. 14), para quem o "metadiscurso envolve aspectos do texto que explicitamente organizam o discurso escrito do ponto de vista do escritor, visando ao conteúdo do texto e ao leitor".

\footnotetext{
* Docente da Universidade Federal do Maranhão e mestranda pelo Programa de Pós-Graduação em Linguística da Universidade Federal do Ceará.

** Docente da Universidade Federal do Ceará com pós-doutorado em Linguística de Texto pela Universidade Estadual de Campinas.
} 
Na presente investigação, analisaremos os marcadores metadiscursivos em redações dissertativas de vestibulandos com o intuito de observar sua importância na construção argumentativa. Buscamos demonstrar que a metadiscursividade é uma estratégia eminentemente argumentativa e que alguns dos recursos metadiscursivos são viabilizados por processos referenciais. A relação entre referenciação e metadiscurso não tem sido explorada, de modo sistemático, na literatura da área, razão pela qual isso será enfatizado neste artigo.

\section{A noção de metadiscursividade}

$\mathrm{O}$ conceito de metadiscurso tem sido recorrente em pesquisas relativas à estrutura textual e à retórica de textos, como, por exemplo: os estudos de metadiscurso em contexto escolar sobre livros didáticos (Crismore, 1989), e em manuais universitários de diferentes disciplinas (Hyland, 1998).

A proposta de Hyland (1998) distinguia duas espécies de estratégia metadiscursiva: a textual e a interpessoal (de natureza retórica). O metadiscurso, na perspectiva textual, seria identificado por meio de operadores textuais, que permitiriam ao leitor entender a intenção do escritor (Hyland, 1998).

Nesta primeira abordagem do autor, o metadiscurso textual seria usado para organizar a informação proposicional de maneira a torná-la coerente para uma audiência específica e para um dado propósito. Os marcadores dessa categoria se voltariam, pois, para a audiência, tendo em vista a avaliação das possíveis dificuldades que o leitor teria com o processamento dos conteúdos proposicionais ali transmitidos, e a necessidade de conduzi-lo a uma dada orientação interpretativa.

Em outras palavras, pode-se deduzir que os elementos do metadiscurso textual ajudariam a caracterizar o perfil do leitor desse texto, e a revelar a que contexto discursivo o texto pertenceria. Assim, eles possibilitariam ao leitor recuperar certos propósitos enunciativos do autor ao tentar orientar a interpretação de significados proposicionais.

Fariam parte do metadiscurso textual os conectores lógicos, os marcadores de enquadramento, os marcadores endofóricos e as referências de conteúdo. Observe-se que, desde essa proposta, alguns mecanismos já envolviam processos referenciais, mas, ainda, em uma perspectiva muito mais ligada à função coesiva dos marcadores endofóricos.

Por sua vez, o metadiscurso interpessoal, segundo Hyland (1998), orientaria os leitores quanto ao modo como o escritor se projetaria nos textos com relação ao conteúdo proposicional e aos próprios leitores. 
A partir desse tipo de estratégia, o leitor seria informado sobre o posicionamento do escritor diante das proposições, contribuindo, assim, para que o sentido do texto surgisse de uma relação escritorleitor. Nessa concepção, o metadiscurso é, essencialmente, interacional e avaliativo.

Fariam parte do metadiscurso interpessoal as formas modalizadoras, os atenuadores, as formas enfáticas, os marcadores de atitude e os marcadores relacionais. O metadiscurso, na perspectiva retórica, entende a escrita como um compromisso social, pois é dessa forma que o escritor se projeta em seu texto, estabelecendo uma relação de persuasão e de orientação.

Essa proposta de Hyland (1998) ainda se concentra, em uma classificação formal de marcadores, dados a priori, e privilegiava a dimensão textual, razão por que não a adotaremos.

O próprio autor parece reconhecer essa limitação quando, na proposta do modelo de 2005, que adotamos para o presente estudo, considera o metadiscurso interacional não apenas como uma estratégia de organização textual, mas como elemento necessário para a argumentação e para diferentes funções discursivas.

O metadiscurso, nesta visão, não pode ser entendido como um fenômeno unicamente linguístico e pragmático (como nas funções da linguagem propostas por Jakobson), nem pode ser entendido exclusivamente como um fenômeno de heterogeneidade enunciativa (como na caracterização de metadiscurso adotada pela Análise do Discurso de orientação francesa); deve ser considerado como um fenômeno retórico e pragmático, como afirma Hyland (1998, p. 15), a seguir, mas também interdiscursivo ao mesmo tempo, acrescentaríamos: "Os traços retóricos podem ser entendidos e vistos não somente no contexto em que eles ocorrem, mas como um resultado metadiscursivo, devendo ser analisados como parte de práticas, valores e ideias de uma comunidade discursiva."

A perspectiva pragmática da linguagem, reforçando a contextualização das realizações verbais, conduz a um encontro entre os procedimentos metalinguísticos e metadiscursivos, na medida em que as referências às estruturas da língua passam a ser observadas no enfoque de seu funcionamento em situações enunciativas.

O metadiscurso, por inscrever o produto verbal na situação enunciativa que o instaura, estabelece uma integração entre enunciado e enunciação. Esta constatação converge também para a noção de metadiscurso em uma perspectiva textual-interativa da Linguística de Texto atual: "uma atividade verbal entre os protagonistas de um ato 
comunicativo, contextualizado no espaço, no tempo e no complexo conjunto de circunstâncias que movem as relações sociais entre os interlocutores" (Risso; Jubran, 1998, p. 2).

A metadiscursividade, assim, potencialmente presente em qualquer manifestação textual e, portanto, em qualquer gênero do discurso, ganha um destaque particular pelo fato de promover a revelação de fatores enunciativos e discursivos na estruturação do texto. O metadiscurso é sempre marcado e, nessa marcação, estão presentes procedimentos verbais de natureza variada.

\section{A proposta de marcadores metadiscursivos de Hyland (2005)}

Foi por se dar conta da supremacia do aspecto interacional em relação ao textual que Hyland (2005) propôs outro modelo em que privilegia o metadiscurso interpessoal. Como parâmetros de análise, o autor dessa visão mais elaborada de metadiscursividade sugere que se considere tanto o posicionamento (stance) como o engajamento (engagement), fornecendo, assim, um modo abrangente e integrado de examinar os meios pelos quais a interação é atingida no argumento.

De acordo com Hyland (2005), esse modelo consolida seu trabalho anterior (1998), por oferecer uma estrutura para analisar os recursos linguísticos do posicionamento intersubjetivo.

Ainda que, nessa proposta, o pressuposto de Hyland (2005) esteja voltado para a escrita dos gêneros do discurso acadêmico, nossa pesquisa utiliza esse modelo para analisar os marcadores metadiscursivos usados em redações dissertativas de vestibulandos, por considerar que os mecanismos apontados pelo autor podem também aplicar-se a qualquer outro gênero. Algumas hipóteses de nossa pesquisa se relacionam à possibilidade de esses marcadores não serem utilizados em textos opinativos do mesmo modo que o são em gêneros acadêmicos.

Este estudo assenta no pressuposto de que todo texto tem finalidade argumentativa e, dessa forma, supõe uma interação entre escritor e leitor, o que já impede que apenas textos acadêmicos busquem a persuasão e desejem merecer crédito em seus argumentos.

Afinal, é a partir de um propósito argumentativo específico (ou mais de um) que é possível expressar uma tomada de posição, calcular as expectativas do interlocutor, que espera também, por seu turno, tornar seu enunciado mais confiável, ou, pelo menos, mais aceitável.

O esquema proposto por Hyland (2005), que abrange o posicionamento e engajamento, encontra-se reproduzido na figura 1 , a seguir: 


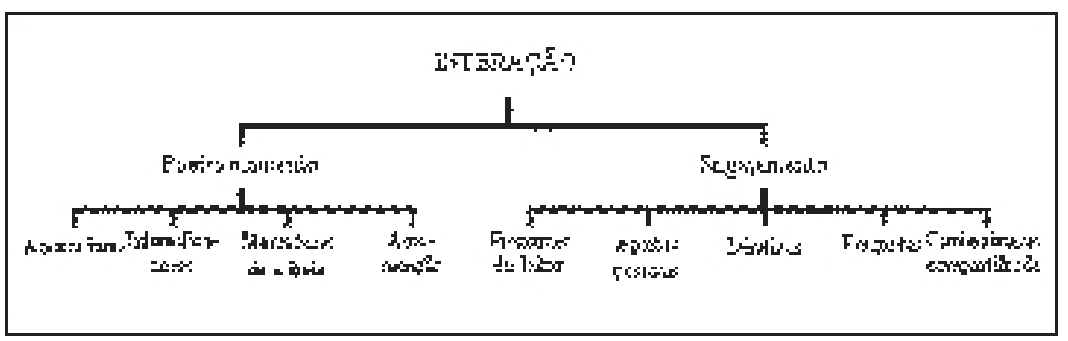

Figura 1: Modelo de Hyland (fonte: Hyland, 2005)

\section{O parâmetro de posicionamento}

O posicionamento é, originariamente, definido como a dimensão que expressa as atitudes do escritor, o modo como ele se apresenta no discurso, como ele constrói seus julgamentos, opiniões e comprometimentos, para demonstrar sua autoridade no meio acadêmico. Nesta pesquisa, essa dimensão será analisada dentro de um gênero produzido para o concurso Vestibular, em que as redações (em nosso caso, as chamadas dissertações) são elaboradas para serem julgadas por uma equipe de professores de Língua Portuguesa que compõe a comissão de correção. Para explicar a proposta de Hyland (2005), utilizaremos, primeiramente, apenas exemplos (aplicados ao Português ${ }^{1}$ ) do discurso acadêmico, tal como fez o autor.

a) Atenuadores - são matizadores discursivos, indicam a força que os escritores calculam para dar à afirmação apenas um certo grau de precisão, tentando torná-lo confiável ao leitor. São recursos como possível, pode, talvez. Expressam, portanto, a imprecisão e a dúvida. É uma estratégia que confere modéstia ao posicionamento e deferência às visões dos colegas, como no seguinte exemplo:

(1) Sobre o ensino da produção escrita muito se tem dito. No entanto, parece que ainda precisamos avançar bastante para conseguirmos unir as pontes que separam as Teorias do texto, as Teorias do discurso e a Didática de línguas. Talvez o primeiro passo seja o seguinte questionamento: como teorias do texto e do discurso podem contribuir com a Didática de línguas, em situação de ensino da escrita? (Artigo científico)

\footnotetext{
${ }^{1}$ Preservamos a identidade dos autores dos exemplos.
} 
b) Intensificadores - são elementos apelativos que, ao contrário dos marcadores de atenuação, expressam certeza, convicção e firmeza, por meio de palavras como claramente, obviamente. Funcionam como uma ênfase dada a uma informação compartilhada:

(2) Só o acompanhamento perceptual e físico pela audiência permite a identificação do referente nos enunciados acima, o que é dispensável no uso simbólico, pois ele renuncia a esse tipo de monitoramento, apesar de exigir, evidentemente, o conhecimento da localização espáciotemporal do emissor como ponto zero do campo dêitico. (Tese de doutorado)

c) Marcadores de atitude - indicam a atitude afetiva do escritor ante as proposições, transmitindo surpresa, concordância, importância, frustração. Exemplos de formas atitudinais são: concordar, preferir, infelizmente, apropriado, observável. O escritor assinala uma necessidade de invocar o leitor a concordar com suas atitudes, julgamentos e reações ante o material investigado, como em:

(3) Por conta da incontestável importância da mídia na Era da Informação é que escolhemos como objeto de análise a construção da argumentação nas crônicas de rádio 'Doa a quem doer'. São comentários de cinco minutos, aproximadamente, sobre fatos que chamam a atenção do público. (...) Analisaremos a utilização de índices de enunciação, de índices lexicais e de índices de organização como recursos utilizados na construção da argumentação desse discurso radiofônico. Dessa forma, estaremos contribuindo para aprofundar o entendimento do funcionamento global do texto, o que, em última instância, é uma importante contribuição para a Linguística do Texto. (Dissertação de mestrado)

d) Automenção - indica a presença ou ausência de uma referência explícita ao autor do texto. É assinalada pelo uso de pronomes pessoais de primeira pessoa, e por pronomes possessivos. Ao empregá-los, o escritor não pode evitar projetar suas impressões no texto em relação a seus argumentos e a seus leitores.

Embora não se costume apontar o caráter dêitico desses marcadores, gostaríamos de chamar atenção para este fato: os marcadores de automenção constituem dêiticos pessoais, aqueles que indicam "a identidade dos interlocutores na situação de comunicação" (Fillmore, 
1971, p. 39). A presença ou ausência desses marcadores dêiticos é, em geral, uma escolha consciente.

Por muito tempo, no discurso acadêmico, evitou-se empregar os pronomes pessoais para poder realçar o fenômeno em estudo, como se as descobertas se evidenciassem por si mesmas. Como argumenta Hyland (2005), isto revela uma ideologia empiricista de tentar mostrar que os resultados seriam os mesmos, independentemente de quem conduzisse a pesquisa ${ }^{2}$. Ainda hoje, podemos encontrar gêneros acadêmicos escritos completamente em terceira pessoa, como em (4), embora a tendência atual seja assinalar, por meio da primeira pessoa do plural (e menos frequentemente da primeira pessoa do singular), o ponto de vista do enunciador ante os dados analisados, como em (5):

(4) É alegado que a transdiferenciação associada ao mecanismo de replicação do tecido cardíaco endógeno para reparo celular pode ocorrer na prática clínica. A proposta atual é de que as células tronco secretam citosinas e fatores de crescimento e promovem angiogênese; suprimem a apoptose dos cardiomiócitos e recrutam outras célulastronco cardíacas. (...) Cada tipo de célula tem suas vantagens, limitações e suas aplicabilidades clínicas. Muitos pesquisadores vêm utilizando células da medula óssea que contêm diferentes populações de células-tronco e progenitoras, incluindo células-tronco hematopoiéticas, células progenitoras endoteliais e células-tronco mesenquimais. (Trabalho de conclusão de curso)

(5) Diríamos que, embora a introdução da obra explicite o objetivo de "descrever o uso dos pronomes pessoais em função das variáveis previstas na própria organização do corpus compartilhado do Projeto NURC" (p. 3), o propósito do trabalho - parece-nos - está menos centrado no aspecto social da linguagem do que na sistematização dos aspectos particulares da estrutura pronominal do português brasileiro. (Resenha acadêmica)

2 "I argue that their treatment is superficial because, despite appearances, it relies solely on a sociological, as opposed to an ethical, orientation to develop a response" (Hyland, 2005, p. 181). 


\section{O parâmetro de engajamento}

Engajamento é a dimensão de alinhamento pela qual o escritor reconhece a presença dos leitores, invocando-os ao longo da argumentação, focalizando sua atenção, de maneira a guiar suas interpretações. Os subtipos são os seguintes:

a) Pronomes do leitor - são marcadores por excelência da inclusão direta do leitor, como você, seu, te. Assim como os marcadores de automenção, também são assinalados por dêiticos pessoais. No discurso acadêmico, em vez de serem usadas as formas dêiticas de segunda pessoa, para trazer mais explicitamente o leitor para dentro do texto, costuma-se utilizar o nós inclusivo, tal como em consideramos, fazemos etc. como em:

(6) Recortando um pouco esse campo vastíssimo de discussão, queremos propor uma perspectiva de análise nessa conjunção/disjunção entre história e retórica, a que diz respeito à figuração do eu nas formas literárias. Ou seja, propomos uma aproximação entre a emergência da subjetividade moderna, cuja data referencial poderíamos situar no final do séc. XVIII (uma subjetividade burguesa, urbana, iluminista, com a hegemonia da idéia-valor do indivíduo) e a sua figuração em determinadas produções textuais, especificamente no gênero romanesco. Em que momento a individualidade entra no mundo do texto? (Artigo científico)

b) Apartes pessoais - expressam a vontade do escritor de intervir explicitamente, interrompendo o argumento, para oferecer um comentário sobre o que está sendo dito. É uma estratégia de orientação do leitor, ao mesmo tempo, pois permite ao escritor responder a uma audiência ativa. É, portanto, amplamente interpessoal, conforme podemos perceber em (7), em que o marcador aliás introduz um aparte pessoal da autora:

(7) Estes universais correspondem, aliás, mais frequentemente a generalidades simplificadas que a conhecimentos aprofundados que se tem o direito de esperar de uma diligência científica. É totalmente possível imaginar uma outra démarche. Uma tentativa que consiste em reconhecer que, apesar dos traços comuns de ordem temática, os contos que vão ser comparados são fundamentalmente diferentes. Trata-se, então, de se perguntar em que eles diferem com respeito aos traços comuns temáticos. (Capítulo de uma coletânea acadêmica) 
c) Diretivas - orientam o leitor a realizar uma ação ou a observar algo de um modo particular. São marcados principalmente pelo imperativo, como considere, note, veja. Além disso, podem ser representados por modalizadores deônticos, como deve, tem que, necessariamente, e por expressões do tipo é importante. Vejamos como isso aparece no exemplo a seguir:

(8) Agora veja que essa mistura ocorre ocasionalmente. Nem sempre que se clicar em um link que deveria levar a uma notícia na íntegra se encontrará esse fenômeno. As notícias digitais não se caracterizam prototipicamente dessa forma. Além disso, bem se vê que um gênero não ocupa o espaço de outro. Naturalmente um depende do outro para se levar ao propósito comunicativo, que é comentar o resultado do jogo, mas cada gênero respeita o espaço do outro harmoniosamente, neste caso. Daí o fato de se dever levar em consideração esse tipo de mescla paralelo à intergenericidade, fenômeno mais conhecido, que será abordado no próximo tópico. (Artigo de anais de congresso)

d) Perguntas - incluem diretamente o leitor no texto ${ }^{3}$. No discurso acadêmico, em geral, as perguntas instam o leitor a refletir sobre o que vai ser discutido no trabalho, como em:

(9) Ao nos depararmos com a trajetória de considerados "gênios" da arte, realizadores de obras inigualáveis que em suas vidas corriqueiras davam mostras de fraca personalidade e de caráter duvidoso, muitas indagações são levantadas: afinal, qual o indivíduo verdadeiro? Qual deles é portador das características essenciais do sujeito? O "gênio" ou o "homem comum"? Acerca desta fissura estabelecida entre o "eu artístico" e o "eu extra-artístico", Foucault apresenta uma discussão bastante interessante, ao trabalhar com a condição de autoria. (Artigo de anais de congresso)

e) Apelo a um compartilhamento - é frequentemente invocado para contestar ideias dentro da argumentação do escritor. Contudo, Hyland (2005) se refere apenas à presença explícita de marcadores pelos quais o leitor é chamado a reconhecer algo como familiar ou aceitável. Fazendo isso, o escritor pressupõe que o leitor sustente certas crenças

\footnotetext{
3 "Is it, in fact, necessary to choose between nurture and nature? My contention is that it is not". (HYLAND, 2005, p.186).
} 
e detenha certos conhecimentos teóricos e metodológicos. Exemplos: Evidentemente, sabemos que..., esta tendência obviamente reflete...

(10) Caso interessante é a questão do editorial, que vai variar muito em seu conteúdo e natureza interna, inclusive estrutural, se for um editorial de revista semanal, tal como a revista Veja, por exemplo, ou um editorial de jornal diário, como no caso da Folha de São Paulo. Sabemos que no jornal o editorial traz a posição do jornal sobre um tema candente no dia [sic]. Mas na revista o editorial é uma visão geral dos temas da semana com uma espécie de motivação para sua leitura. E se formos observar o editorial de uma revista masculina ou de revistas científicas, cada vez vai ser outra coisa, ou seja, o suporte vai interferir. Será que temos sempre um editorial ou já temos cada vez outro gênero? (Apresentação de pôster)

Posicionamento e engajamento são, dessa forma, dois lados da mesma moeda e constituem a dimensão interpessoal do texto/discurso.

O metadiscurso exerce também funções semântica, social e psicológica, permitindo-lhe exercer certo controle em uma situação comunicativa.

A proposta de Hyland (2005) defende uma visão em que a interação entre autor e leitor se torna um elemento importante para o desenvolvimento da noção de metadiscurso. As categorias posicionamento e engajamento tornam-se a base da nossa análise porque essa noção é fundamental na observação de como a interação enunciador e co-enunciador se constrói em um texto para a eficácia da argumentação e, em vista disso, para a construção de sentido via referente.

Para Hyland (2005, p.78), "o metadiscurso é a manifestação linguística e retórica do autor no texto para organizar o discurso". Dessa forma, pode-se considerar que toda estratégia metadiscursiva é argumentativa. Do mesmo modo, podemos afirmar que toda escolha de modos de designar referente supõe, também, uma finalidade argumentativa. Nesse sentido, todo emprego de expressão referencial é argumentativo e, ao mesmo tempo, metadiscursivo em sentido amplo, embora esta última consideração não seja dita explicitamente por Hyland (2005).

\section{Uma aplicação aos dados}

Os operadores metadiscursivos serão analisados dentro de um texto dissertativo, que se enquadra na sequência argumentativa. Para a 
consideração desse aspecto composicional de nosso corpus, utilizaremos a perspectiva de Bronckart (2007), para assim ressaltar a importância desses operadores na construção argumentativa e, também, a função deles no processo de referenciação.

Uma sequência argumentativa visa a defender um ponto de vista, uma tese, mas apresentando gradativamente os argumentos para sustentá-la, por isso, segundo Bronckart (2007), ela se constitui das seguintes fases, de modo simplificado:

(a) tese inicial - contextualização ou inserção da orientação argumentativa, propondo uma constatação de partida;

(b) argumentos - dados que orientam para uma conclusão provável;

(c) contra-argumentos - dados que se opõem a uma argumentação;

(d) conclusão - nova tese - em função dos efeitos dos argumentos e contra-argumentos.

Nesta pesquisa, observamos 15 redações de Vestibular. Mostraremos, por falta de espaço, a análise completa somente de uma delas, que se encontra reproduzida a seguir (mantivemos o original tal como estava):

Saudade é um baú de sentidos vividos

Dizer sobre os sentidos da palavra saudade é revisitar momentos bem guardados, escondidos mesmo, nos recônditos da alma. Lugar este pouco visitado, uma espécie de baú a guardar os melhores momentos de nossa vida e por isso mesmo o evitamos, pois este "baú" é construído pelo tempo e jamais devolve seus pertences.

Podemos dizer que a palavra saudade tem tantas possibilidades de sentido que seria impossível enumerá-las pois se confundem com nossas experiências mais sublimes e se constroem por toda a vida. Para uma boa e longa vida, então, mesmo um livro ainda seria pouco para contá-las.

Sabemos traduzir a palavra saudade, mas não conceituá-la. É como água entre os dedos, escapando a qualquer limitação terminológica, compreendêmo-la apenas mergulhando na memória, remexendo em cicatrizes que desejamos nunca saírem. Diria Fernando Pessoa: "é umar?? Assim, meio odiosamente". 
Os sentidos desta palavra se confundem com nossa trajetória de vida. Ao traduzi-la podemos invocar nossas amizades na infância, um grande amor, aquele abraço materno com um segundinho a mais que o tornou especial. Enfim, o que há de comum entre estes fatos é que temos a certeza de que jamais se repetirão. Resta-nos deles apenas a saudade.

Saudade é uma palavra sem significado próprio, de sentidos escritos pelo tempo, guardada em baús empoeirados da alma, dos quais às vezes sentimos saudades, revisitamos e fechamos novamente de olhos vermelhos e coração saudoso. (Redação, 2007)

Para estabelecer uma relação entre o esquema da sequência argumentativa e os marcadores metadiscursivos, propusemos os seguintes quadros analíticos (ver quadros 1, 2, 3 e 4), em que também estão inseridos os processos referenciais ligados a estratégias metadiscursivas discriminadas por Hyland (2005):

\begin{tabular}{|c|c|c|c|}
\hline \multicolumn{4}{|c|}{ 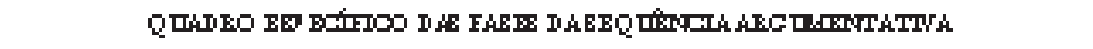 } \\
\hline \multicolumn{4}{|c|}{ Aquavabiva } \\
\hline Yminn & Angumm la & Can Imxyumm la & مivandur \\
\hline 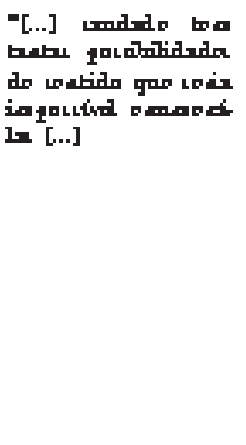 & 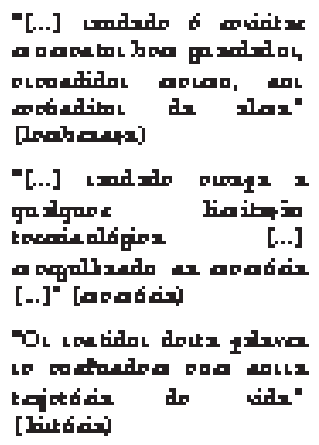 & 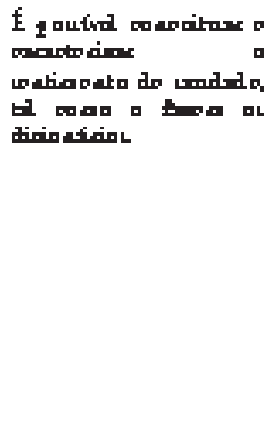 & 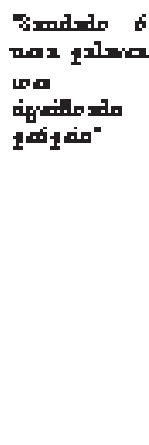 \\
\hline
\end{tabular}

Quadro 1: Quadro específico das fases da sequência argumentativa de Bronckart (2007) 


\begin{tabular}{|c|c|c|c|}
\hline \multicolumn{4}{|c|}{ 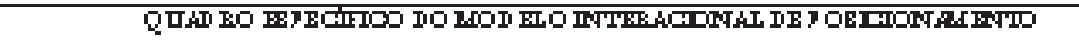 } \\
\hline Amnuedar & In $\ln$ uiEmadn r & Harmide $\mathrm{r}$ de 26 ude & Ambmenpion \\
\hline 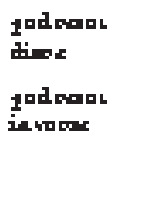 & & 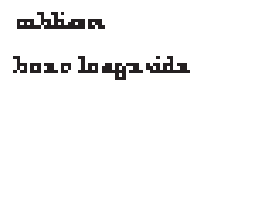 & 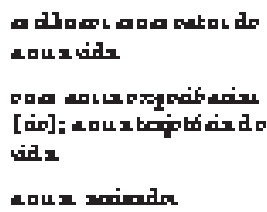 \\
\hline
\end{tabular}

$(2005)$

\begin{tabular}{|c|c|c|c|c|}
\hline \multicolumn{5}{|c|}{ 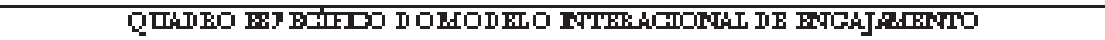 } \\
\hline $\begin{array}{c}\text { Oraname da } \\
\text { Jaibr }\end{array}$ & $\begin{array}{l}\text { Apurb: } \\
\text { paraxis }\end{array}$ & Dimita & Yargun b & $\begin{array}{l}\text { Canhwimen b } \\
\text { momprilhadd }\end{array}$ \\
\hline 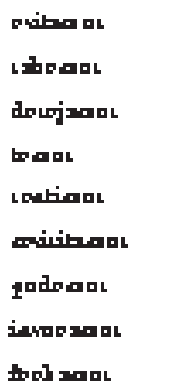 & & & & 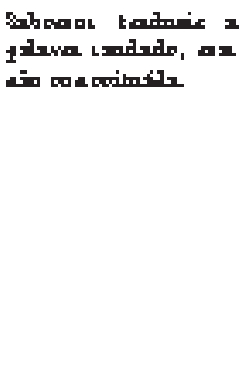 \\
\hline
\end{tabular}

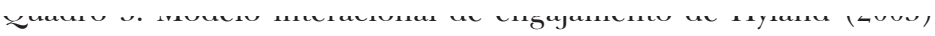

\begin{tabular}{|c|c|}
\hline \multicolumn{2}{|c|}{ 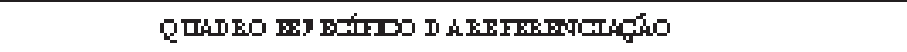 } \\
\hline 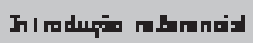 & Anilo re \\
\hline & 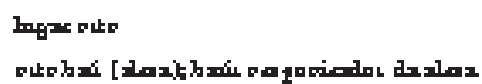 \\
\hline
\end{tabular}

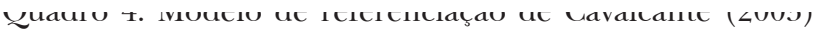


A premissa (tese inicial), que não precisa vir explícita, encontrase no segundo parágrafo, na afirmação de que "saudade tem tantas possibilidades de sentidos que seria impossível enumerá-las", por se confundir com as experiências de toda uma vida.

Para reforçar essa premissa, o vestibulando argumenta no primeiro parágrafo que saudade é "[...] revisitar momentos bem guardados, escondidos mesmo [...]", destacando, assim, que um dos sentidos de saudade é lembrança. $\mathrm{O}$ argumento do terceiro parágrafo repete a impossibilidade de a saudade ser conceituada e novamente indica que ela é memória.

No quarto parágrafo, o vestibulando, mais uma vez, argumenta que saudade é história, pois os sentidos desse sentimento se confundem com as experiências e trajetórias de vida. Essa repetição do argumento confirma uma de nossas hipóteses: a de que os argumentos, em geral, não são desenvolvidos pelo aluno, uma vez que, muitas vezes, ele só os repete, preocupando-se apenas com a continuidade temática (Costa Val, 1991), mas não com a progressão, nem com a informatividade. Para reforçar a tese, que pode ser resumida por "[...] saudade tem tantas possibilidades de sentido que seria impossível enumerá-las [...]”, ele não estaria impedido de relacionar história, memória e lembrança. Todavia, da forma como o fez, elimina o que poderia haver de acréscimo argumentativo, porque, além de ele não desenvolver os argumentos, a ordem não resultou em uma sequenciação. Explicamos: ele poderia ter construído com uma anáfora encapsuladora não simplesmente um argumento, mas também uma sequenciação argumentativa. Por exemplo, a palavra história seria a primeira raiz da saudade, que poderia avançar para duas direções: a memória, muito mais presa à realidade, e a lembrança, à imaginação. Esse recurso, inclusive, poderia ser uma opção que favoreceria a organização dos argumentos, de tal forma que, no desenvolvimento, o candidato não incorreria em repetição, isto é, na mera continuidade temática.

Mesmo com o contra-argumento implícito, o vestibulando conclui que "saudade é uma palavra sem significado próprio". Pode-se perceber que a palavra próprio é uma impropriedade vocabular, pois todos os argumentos reforçam a tese de que saudade tem tantas possibilidades de sentido que "escapam a qualquer limitação terminológica". Mais do que uma impropriedade, é uma contradição, o que faz comprometer, como explica Val (1991), a coerência nesse ponto do texto.

Entretanto, as inúmeras possibilidades de sentido da palavra saudade ficam reduzidas a um só: lembrança, ainda que textualmente 
haja referência à história e à memória. Dessa forma, pode-se perceber que os argumentos apenas se repetem, prejudicando a sequência argumentativa.

Evidentemente, os problemas apontados no desenvolvimento da sequência argumentativa se refletem na escolha de marcadores metadiscursivos - a hipótese básica de nossa pesquisa. Uma das constatações mais importantes a que chegamos, após a análise das 15 redações, foi a estreita relação entre a sequência dominante de um texto dissertativo e o propósito enunciativo do enunciador, além do propósito comunicativo convencionado para o próprio gênero.

Os operadores metadiscursivos usados pelo vestibulando para marcar posicionamento foram os atenuadores "podemos dizer" e "podemos invocar", ambos também fazem parte da dimensão do engajamento, como pronomes de leitor. Esses dois exemplos demonstram como alguns operadores se sobrepõem. Isso acontece porque, ao mesmo tempo em que o enunciador se posiciona, ele convoca o leitor para uma relação dialógica. Por meio da sobreposição, ele conquista o leitor, porque há, entre a tomada de posição e a busca de adesão do leitor, em uma relação de causa e efeito, um dos princípios que justificam a própria argumentação.

A anáfora correferencial este baú é recategorizadora e pode ser considerada como operador metadiscursivo de posicionamento como um marcador de atitude. Isso porque, ao renomear um objeto já representado, marca uma atitude subjetiva. Ao final do texto, ela é novamente recategorizada como baús empoeirados da alma.

Não se pode negar, desse modo, que algumas estratégias metadiscursivas se utilizam de processos referenciais. Todavia, nossos dados revelaram que, pelas dificuldades enfrentadas pelos vestibulandos para organizar, composicionalmente, uma sequência argumentativa, eles terminam por não articular bem os tópicos e os argumentos, o que compromete a continuidade e a progressão temática e redunda em outro problema: o mau uso de expressões referenciais. Assim sendo, certos operadores metadiscursivos referenciais, que não deveriam ser importantes somente por sua presença no texto, mas pela marca da atitude do produtor no seu discurso, acabam por ser insuficientes e inadequados para retomar, trazer informação nova ou para dar continuidade às proposições. 


\section{Considerações finais}

Esta pesquisa nos fez concluir que qualquer classificação de marcadores metadiscursivos há de ser sempre uma lista aberta, quase nunca definida a priori, pois os recursos convocados pelo enunciador para se posicionar discursivamente e para engajar o leitor na orientação argumentativa pretendida dependem de várias condições contextuais e dos próprios objetivos do autor. Um dos propósitos do presente estudo era verificar que marcadores metadiscursivos costumam ser empregados pelos alunos, com a finalidade de refletir sobre as dificuldades que eles encontram ao relacioná-los com a construção argumentativa.

Observamos, com a análise das redações, que, por vezes, há uma sobreposição nos marcadores, pois não só invocam o leitor como assinalam a posição do emissor, o que comprova que as dimensões de posicionamento e de engajamento são duas faces da mesma moeda. Por outro lado, percebemos que, embora algumas formas metadiscursivas sejam previsíveis na língua, como os marcadores de automenção e os pronomes do leitor, porque são manifestados por dêiticos pessoais; e embora haja alguma previsibilidade para os atenuadores e para os intensificadores, como formas de modalização da língua, a maioria dos demais tipos não pode ser previamente determinada.

Os dados revelaram a estreita relação, também variável, entre as fases (macroproposições) de uma sequência argumentativa e o emprego de estratégias metadiscursivas. Não se pode falar de uma relação direta entre tipos de marcadores metadiscursivos e uma dada fase da sequência argumentativa, mas é possível atestar que a seleção de recursos metadiscursivos depende da introdução de dados para ampliação da tese inicial, ou da contra-argumentação, ou do reforço da conclusão da nova tese. A relação entre metadiscursividade e argumentação se mostrou, no entanto, problemática em nosso corpus, porque, em várias redações, havia um posicionamento frágil do autor e sem qualquer tentativa de engajamento do leitor, visto que os argumentos ou se contradiziam entre si, ou não eram condizentes com a tese inicial. Tudo isso contraria os princípios de uma sequência argumentativa.

Por fim, vale sugerir que pesquisas futuras aprofundem os tipos de função metadiscursiva que os processos referenciais anafóricos e dêiticos podem desempenhar em gêneros diversos e que se investiguem quais desses processos podem corresponder a estratégias de posicionamento e de engajamento. 


\section{Referências bibliográficas}

BRONCKART, Jean-Paul. Atividade de linguagem, textos e discursos: por um interacionismo sociodiscursivo. São Paulo: EDUC, 2007.

CAVAlCANTE, Mônica M. A construção do referente no discurso. Curso de formação Continuada de Professores da Rede Pública; Universidade Aberta do Nordeste - Fundação Demócrito Rocha - Fortaleza, fascículo 7, 2003.

CRISMORE, A. Talking with readers: metadiscourse as rhetorical Act. New York: Peter Lang, 1989.

FILLMORE, Charles. Lectures on deixis. Berkeley: University of California, 1971.

HYLAND, K. Persuasion and context: The pragmatics of academic metadiscourse. Journal of Pragmatics, Hongkong, no 30, p. 437-455, 1998. . Stance and engagement: a model of Interaction in Academic Discourse. In: Discourse Studies. Sage publications, 2005.

RISSO, Sanfelice Mercedes, JUBRAN, Clélia Cândida A. Spinardi. O discurso auto-reflexivo: processamento metadiscursivo do texto. D.E.L.T.A. [online], v. 14, n. especial, 1998. Disponível em: <http://www.scielo.br/ scielo.php?script=sci_arttext\&pid=S0102- 44501998000300012\&lng=en\& nrm=iso $>$. Acesso em: 14 Fev. 2008.

VANDE KOPPLE, W. Some exploratory discourse on metadiscourse. In: College Composition and Communication, v. 36, p. 82-93, 1985. 


\title{
Resumo
}

Neste artigo, propomos uma articulação entre os marcadores metadiscursivos (Hyland, 2005), a sequência argumentativa (Bronckart, 2007) e alguns processos referenciais, como as anáforas recategorizadoras e os dêiticos de pessoa (Cavalcante, 2003). Para isso, analisamos 15 redações do concurso Vestibular da Universidade Federal do Maranhão e apresentamos um exemplo de como poderia ser estabelecida essa relação. Constatamos que os problemas de uso de recursos metadiscursivos, dentre eles os processos referenciais, se devem à dificuldade do aluno em tornar mais consistentes os argumentos que o conduzam à tese final.

Palavras-chave: metadiscurso; argumentação; referenciação.

\begin{abstract}
In this article, we propose an articulation between the metadiscursive markers (Hyland, 2005), the argumentative sequence (Bronckart, 2007) and some referential processes, such as encapsulating anaphors and the personal deictics (Cavalcante, 2003). For that purpose, we analyzed 15 essays from the Vestibular exams for the Universidade Federal do Maranhão and presented an example of how this relationship could be established. We observed that the problems regarding the use of metadiscursive resources, including referential processes, are due to the difficulty that students have in shaping consistent arguments that lead to the final thesis.
\end{abstract}

Key words: metadiscourse; argumentation; referentiation. 